\title{
MIR137 Pre-miRNA
}

National Cancer Institute

\section{Source}

National Cancer Institute. MIR137 Pre-miRNA. NCI Thesaurus. Code C82769.

Pre-MIR137 (102 bases) is encoded by the human MIR137 gene. This olig oribonucleotide may play a role in transcriptional silencing. 